\title{
'The decline and fall of hospital paediatrics' 23 years after
}

When Douglas Gairdner predicted the imminent decline and fall of hospital paediatrics he was assuming that in a relatively affluent and competent society, for which the zymotic diseases were losing their terrors, the inpatient units that we had developed would lose their raison d'être once the purposes for which they had been founded had been more or less achieved. ${ }^{1}$

Hospitals were originally places to which the indigent poor resorted when their homes could not provide the conditions needful for their care and cure, or where they were sent either because it was thought that they were infectious and therefore dangerous to the rest of the community or because the sufferer had become a charge on the parish. It was therefore only relatively late in the development of medical services that hospitals for children were founded since it could be assumed in most cases that their best care-takers would be their own families-unless they were foundlings or orphansand that away from their families they were likely to pine rather than to recover.

The children's hospitals grew out of the dispensaries ${ }^{2}$ that provided rudimentary primary care for those children whose poor parents were unable to pay for the services of a physician or apothecary when it was recognised that in many cases home conditions were such as to be inimical to their recovery or rehabilitation. But as in adult medicine, hospitals provided a setting in which physicians were able first to categorise and then to study scientifically the diseases that had led to admission; and this proved to be the essential preliminary to developing measures for prevention or treatment. Usually such physicians were generalists who, while earning their living in private practice, devoted their public practice to the study of a specialty - of which paediatrics became one. Thus initially paediatrics became the study of diseases peculiar to children rather than the general medicine of childhood; and this distinction is one that has ever since bedevilled the relations between paediatrics and what has now become adult medicine.

The separate development of the children's hospitals-such as the Royal Manchester Children's Hospital and Great Ormond Street, the children's wards in the general and university hospitals, the isolation hospitals whose clientele were mainly children, and the workhouses with their infirmaries, also led to divisions in paediatric practice which we are still trying to sort out and overcome. Generally, the children's hospitals succeeded in the task of identifying and arriving at some understanding of the illnesses of childhood as they then were, and in developing a corps of children's doctors, nurses, and ancillary workers with experience in dealing with children.

Paediatrics as a separate specialty developed late; it was difficult in Britain to earn a living from private paediatric practice, and it was only after the second world war, with the establishment of the NHS and the provision of free medical care for women and children, as well as for insured workmen, that physicians with an interest in the diseases of childhood and no private income were able to devote themselves totally to paediatrics: in fact Gairdner's generation must have been the first in which physicians could make it a full-time career. These physicians inherited the facilities and traditions of the various children's hospitals and units which had been developed throughout the country and, reinforced by refugees from countries with a tradition of paediatric practice (for instance in Manchester the institutions founded by Merei and Borchardt in the 1850s), and by experience in the great American paediatric hospitals, they were able to take full advantage of the therapeutic explosion that began with the development of effective chemotherapy. Thus within a decade their wards began to empty and paediatrics became, like chest medicine, one of the specialties which could be said to have fulfilled its mission.

This was the situation when Gairdner wrote his article; and its influence was the greater because of doubts about what may be called the negative aspects of hospital care; separation from home and family, the interruption of schooling, the need for constricting discipline in a busy ward, and the possibilities for cross-infection. It was the time when Bowlby's views on separation became common knowledge, when the St Mary's home care scheme was established, and when all-day visiting, hospital schools, and ultimately, facilities for play in hospital became de rigueur-changes which had the important side effect of totally altering the role of children's nurses from substitute mothers into the givers of support to visiting mothers (and injections) and which may be partly responsible for our present difficulties in recruiting children's nurses.

Donald Winnicott put it very well in an unpublished letter to Robert Tod defending the new attitudes: 'I became a Physician in charge of my 
own Department at the Paddington Green Children's Hospital in 1923 and retired after 40 years. In the course of that time there was a gradual shift in the work of the Department from physical illness to emotional disturbance or to the psychological aspect of the personality if one uses the word psychological without specifically linking it with academic psychology.

'At the same time I had an appointment of a similar nature in the decade 1923-33 in the East End at the Queen's Hospital for Children, now Queen Elizabeth's. Here I saw a very large number of patients and was in charge of the LCC Rheumatism Clinic which dealt with rheumatic fever and chorea and concomitant heart disease.

'We also had to deal with very severe summer diarrhoea and various polio epidemics and, of course, those were the days before antibiotics so that our wards were full of children with pus in the lungs, the bones, or the meninges. Penicillin put a stop to all that and transformed physical paediatrics into something which could afford to look at the disturbances that belong to the lives of children who are physically healthy. In a way, therefore, the advances of physical paediatrics opened up the field for child psychiatry. I tried to make full use of this new development.'

Many paediatricians still in practice will be able in their mind's eye to contrast the spick and span wards of their professional childhood with their rows of tidy beds and lockers, their institutionalised inmates, and their well-organised routines with the present informality. The substitution of an endofor an exo-skeleton does not of course necessarily imply a loss of efficiency.

But structures are not so rigid that they cannot be adapted to new circumstances, and progress in medicine is like that of the hill walker who on gaining one summit gets his first view of the next. In more or less conquering the zymotic diseases and their after effects we gave ourselves the opportunity of tackling properly a whole range of problems including those of the handicapped child, those posed by the newborn baby, and those resulting from congenital abnormalities both structural and biochemical; moreover there is still plenty of work for a short-stay hospital ward whether in terms of investigation (such as those necessary to determine the aetiology of short stature), for observation (as in cases of unwell babies at risk of sudden death), for evaluation (as in cases of suspected inflicted injury), and for treatment (as in the case of status asthmaticus, diabetic keto-acidosis, leukaemia, and intensive care). Thus $45 \%$ of the sample of children followed in the National Child Development Study were admitted to hospital by age 7 years. ${ }^{3}$

The number of available beds has not in fact changed greatly though recently there have hardly been enough trained nurses to man them as a result of what we must consider mistaken policies emanating from the General Nursing Council. Administrators who measure efficiency by bed occupancy and who do not understand that bed occupancy and turnover are necessarily inversely related should be made to recognise that beds in which there is no turnover will always be occupied and that to ensure a good turnover with the minimal length of stay that is best for children and no waiting, a large proportion of beds must be free at any one time. In fact maximum usage of beds depends on filling them from a waiting list with minimum delay which is incompatible with coping efficiently with a large emergency load and is a great strain on nursing staff. The available beds could however be better used if no children were nursed in nonpaediatric wards (including those in isolation hospitals), which despite Platt they still are, and if we had enough trained nurses.

Thus it did not need the application of Parkinson's Law to keep the children's wards turning over. ${ }^{4}$ We should be less complacent about the growing need to admit children with relatively trivial illnesses from materially 'good' homes because their mothers are at work and cannot look after them; but while women continue to believe that they will get the best rather than the worst of both worlds by trying to hold down a job as well as rearing a young family, the hospital will have to back up the nursery in this way. So it is that, contrary to Gairdner's prediction, the children's units remain nearly as busy as they ever were; and we are now less worried about separation which is mitigated by short-stays and all-day visiting and where ill effects have been shown to be related as much to home as to hospital conditions: indeed some children only thrive in hospital. ${ }^{5}$

What of the future? Looking at the present work of the paediatrician, it is clear that it comprises three main activities: the out- and inpatient care of acute and chronic illness, which includes investigation as well as nursing and treatment; involvement in child care in the home and at school, and especially with the assessment and amelioration of handicap; and the sometimes intensive care of the vulnerable newborn. We also need to recognise that our patients come from the maternity hospitals and are passed on to the general hospitals and that in the case of adolescents now surviving protracted and serious illness in childhood-such as cystic fibrosis, malignant disease, inborn error, muscular dystrophy etc.- - the handover may be traumatic and can expose them to danger when neither the adult physician nor the GP is experienced in the kind of care that they need.

Paediatrics has now developed to the point where 
most physicians dealing with adult patients acknowledge that the paediatric physician has more to offer the sick child; and in these circumstances demarcation disputes should be a thing of the past with the paediatrician dealing with those children brought to the doctor by their parents or guardian and the internists with those seeking a consultation of their own volition. Some physicians may reasonably want to share the care of certain patients with their paediatric colleagues in the children's wards; and in exchange they should perhaps offer beds and help to paediatricians whose patients have outgrown the facilities of a children's unit! It seems obvious that isolated comprehensive children's hospitals will have less to offer in the future than units sharing a campus with obstetric and general hospitals; and that it should be acknowledged that adult medicine and paediatric medicine need also to share their knowledge (each has so much to learn from the other) in caring adequately for children with advanced organ system disease. In this field one foresees the development of combined medical and surgical units run jointly by paediatricians with an interest in an organ system and organ system specialists with an interest in children. Such a children's unit would need its own building (though with link corridors to the obstetric and general hospitals sharing the site), its own ancillary staff, a children's trained nursing staff not at the beck and call of senior nursing officers on the adult side, its school, and its subdepartments of radiology and pathology. It would operate mainly as a polyclinic with only enough beds -including day beds, planned investigation beds, observation beds, and an intensive care unit - to serve its outpatient department, assessment unit, and casualty departments; and the last would in city centres provide a hospital-based primary care service run by the local GPs or department of general practice. ${ }^{6}$ The children's unit should also house the departments of child psychiatry and paediatric surgery and, very important, anaesthetics, and be closely linked with the department of genetics. The paediatric division would provide a forum for all those in paediatric care whether at primary, secondary, or tertiary level. Such a unit might well in most cases serve an area rather than a district, especially in conurbations, as well as making its regional contribution.

Identity having been acknowledged, collaboration between equals is possible and desirable. But in certain respects we need to maintain autonomy; and we have links with obstetrics as well as with medicine, surgery, and psychiatry. As a major part of general medicine (that of childhood) we have properly remained within the College of Physicians; but if, in order to regulate our training and to give repre- sentative advice to government, we need to establish our own faculty, we could perhaps ask the adult physicians in equity to do the same. As regards the British Paediatric Association, perhaps it could revert to its original aims-modelled on those of the Association of Physicians - of sharing advances in knowledge and promoting friendship between members. But if paediatrics is to continue to thrive, we must put the service and the discipline first in our loyalties and not our institutions however venerable and famous. Douglas Gairdner was right in seeing that an era had come to an end; but it was not that of hospital paediatrics but that of isolated paediatric hospitals. The future lies in collaboration with our colleagues in other specialties as well as with the development of our own specialties, for paediatricians are essentially general physicians both by inclination and because of the nature of most of their work, which is concerned with the origins rather than the results of disease. This is where our contribution to the prevention of ill health in adult life will be important; and perhaps in that context we can look forward to the decline and fall of all hospital medicine and even of the maternity hospitals.

In common with all paediatricians, I am indebted to Douglas Gairdner for making me think about the current problems and their possible solutions. I am grateful to Dr D. H. Vaughan of the Manchester Regional Health Authority for supplying the relevant national and regional statistics, and to Mr T. Ibison, Sector Administrator, Royal Manchester Children's Hospital, for allowing me to study Mr I. T. Wood's unpublished MSc thesis 'Report on RMCH. An OR-based examination of the performance characteristics of the Royal Manchester Children's Hospital'.

\section{References}

${ }^{1}$ Gairdner, D. (1956). The decline and fall of hospital paediatrics. Proceedings of the Royal Society of Medicine, 49, 974-975.

${ }^{2}$ Loudon, I. S. L. (1979). John Bunnell Davis and the Universal Dispensary for Children. British Medical Journal, 1, 1191-1194.

${ }^{3}$ Davie, R., Butler, N., and Goldstein, H. (1972). From Birth to Seven. The Second Report of the Child Development Study (1958 Cohort). Longmans: London (in association with the National Children's Bureau).

${ }^{4}$ Wynne, J., and Hull, D. (1977). Why are children admitted to hospital? British Medical Journal, 2, 1140-1142.

${ }^{5}$ Quinton, D. (1979). The long-term effects of hospital admissions in childhood. Journal of Maternal and Child Health, 4, 190-195.

${ }^{6}$ Komrower, G. M. (1977). The role of the hospital in primary care for the child in the community. British Medical Journal, 2, 787-789.

J. A. Davis

Department of Paediatrics, University of Cambridge Clinical School, Addenbrooke's Hospital, Cambridge, CB2 $2 Q Q$ 